\title{
Comparative Carbohydrate Catabolism in Arthrobacter
}

\author{
By A. C. ZAGALLO AND CHIH H. WANG \\ Department of Chemistry and Science Research Institute, \\ Oregon State University, Corvallis, Oregon, U.S.A.
}

(Received 9 November 1961)

\begin{abstract}
SUMMARY
The catabolic pathways for the utilization of glucose and gluconate in one representation of each of five species of Arthrobacter were studied by the respirometric method (Wang et al. 1958). The results indicate that these Arthrobacter organisms can be classified into two groups on the basis of their catabolic behaviour. The first group (Arthrobacter ureafaciens, A. globiformis) relies primarily on the operation of the Embden-MeyerhofParnas pathway and, to some extent, the hexose monophosphate pathway for the assimilation of glucose. In the second group (A. simplex, A. pascens, $A$. atrocyaneus) glucose is catabolized primarily by way of the intermediary formation of gluconate; the Entner-Doudoroff and the hexose monophosphate pathways appear to be the major routes for the assimilation of glucose and gluconate.
\end{abstract}

\section{INTRODUCTION}

Conn (1928) first called attention to the occurrence in soil of a bacterium which exhibited a very striking pleomorphism in the sense of changing from a distinct rod in young cultures to a coccoid form in older cultures, after passing through an elementary life cycle. Although morphologically resembling Corynebacterium, Conn named the soil bacterium in question Bacterium globiforme. Subsequently, Conn \& Dimmick (1947) proposed the name Arthrobacter for the inclusion of the pleomorphic soil micro-organisms which, in contrast with the animal diphtheroids, liquefy gelatin, do not produce acid from fermentable sugars, are urease negative and grow well on simple defined media with inorganic nitrogen sources. The new genus has been given recognition in the current edition of Bergey's Manual (1957). Although many microbiologists felt that the soil globiform group ought not to be included in the genus Corynebacterium, the present taxonomic status of the genus Arthrobacter is still a subject of much controversy. Lochhead \& Burton (1957) and Lochhead (1958), while investigating the dominant soil microflora, isolated and characterized several bacterial species, some of which require amino acids, others being dependent to different degrees upon growth factors. $A$ few of these species were assigned to the genus Arthrobacter on the ground of morphological resemblance, in spite of pronounced differences in nutritional requirements. There are nine Arthrobacter species listed in Bergey's Manual (1957) which have been brought together mainly on account of their peculiar cell morphology, uneven staining and incidental motility; species characterization according to their physiological behaviours has not been very rewarding. Taylor (1938), summarizing his extensive 
work on the utilization of sugars by strains of $B$. globiforme, stated that the findings were so inconsistent and changeable that it was practically impossible to classify these organisms on the basis of acid production from sugars. In fact, one finds in the literature many detailed descriptions of the unusual pleomorphism and life cycles exhibited by this interesting soil organism (Conn \& Dimmick, 1947; Lochhead \& Burton, 1953; Sacks, 1954; Chaplin, 1957; Lockhead, 1958; Sundman, 1958), whereas studies of its physiology are notably scanty. Moreover, the genus Arthrobacter has gradually expanded beyond the commonly held definition of the typespecies, $A$. globiformis, an organism which possesses remarkable synthetic abilities and grows well in simple media containing inorganic nitrogen and no growth factors. Thus, the organism, $A$.terregens (Lochhead \& Burton, 1953), requires amino nitrogen, biotin, thiamin, pantothenic acid and the 'terregens factor' for proliferation, but is nevertheless included in the genus Arthrobacter.

The Arthrobacter organisms constitute an important fraction of the soil indigenous microflora, yet little is known with regard to the catabolic mechanisms functioning in these organisms. With Arthrobacter ureafaciens (Corynebacterium creatinovorans), Ghiretti \& Barron (1954) reported that hexoses were catabolized by a pathway involving pentose and sedoheptulose as key intermediates. The occurrence of the Embden-Meyerhof-Parnas (EMP) pathway in this organism was ruled out on the grounds that glucose cannot be utilized by this organism under anaerobic conditions, although several enzymes in the EMP sequence were reported to be present. In so far as the catabolism of breakdown products of glucose is concerned, these authors suggested that acetate is oxidized via the 'dicarboxylic acid cycle'. However, Fukin \& Vandermark (1952) reported evidence supporting the operation of the tricarboxylic acid cycle (TCA) in this organism. Morris (1960) reported that in $A$. globiformis glucose is catabolized mainly (65\% of the substrate glucose) by the EMP pathway and to a limited extent (35\%) by the hexose monophosphate (HMP) pathway. Pyruvate, a key degradation product of glucose, was reported to be oxidized mainly via the TCA cycle mechanism. In the present work, the catabolic mechanisms for the assimilation of glucose and gluconate in single strains of each of five species of Arthrobacter have been examined comparatively by the radiospirometric method (Wang et al. 1958). The findings provide information for a better understanding of biochemical behaviour and phylogenetic relationships with regard to these organisms.

\section{METHODS}

Organisms. One strain of each of five species of the genus Arthrobacter were used in this study. They were: Arthrobacter globiformis, ATCC No. 8010; A. ureafaciens, ATCC no. 7562; $A$. simplex, ATCC no. 6946; $A$. pascens n. sp.; $A$. atrocyaneus sp. The first three were obtained from the American Type Culture Collection (ATCC). A. pascens and A. atrocyaneus (Kuhn \& Starr, 1960) were obtained through the courtesy of the Microbiology Research Institute, Department of Agriculture, Ottawa, Canada, and the Department of Bacteriology, University of California at Davis, respectively. The stock cultures were maintained on nutrient agar slopes (with $0.05 \%$ yeast extract) and kept in the refrigerator (at about $6^{\circ}$ ) until ready to use.

Media. The media used for growing the organisms are given in Table 1. Glucose and some of the other constituents were sterilized separately by autoclaving for $10 \mathrm{~min}$. at $120^{\circ}$, and mixed asceptically when cool. 
Growth of organisms. All organisms were grown in about $100 \mathrm{ml}$. of liquid media in $250 \mathrm{ml}$. Erlenmeyer flasks and incubated on a rotary shaker at $\mathbf{2 8}^{\circ}$. Three serial transfers from the stock culture, at suitable time intervals, were made before harvesting the organisms. Organisms in the logarithmic stage of growth were used for the radio-respirometric experiments.

Table 1. Growth conditions for the Arthrobacter strains used

Organism

Arthrobacter
ureafaciens
A. globiformis
A. simplex

A. pascens and A. atrocyaneus
Medium used by Morris, slightly modified. $\left(\mathrm{NH}_{4}\right)_{6} \mathrm{Mo}_{7} \mathrm{O}_{24} \cdot 4 \mathrm{H}_{2} \mathrm{O}$ and $\mathrm{Co}\left(\mathrm{NO}_{2}\right)_{2} \cdot 6 \mathrm{H}_{2} \mathrm{O}$

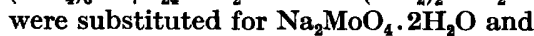
$\mathrm{CoSO}_{4}$, respectively. $\mathrm{K}$ gluconate was used as sole source of carbon. $\mathrm{pH} \mathrm{7 \cdot 0}$

As above but with glucose used as sole carbon source

Morris medium with phosphate concentration reduced to $1 / 8$ and addition of yeast extract $(0.04 \%)$ and a trace of vitamin $B_{12}$. Glucose as sole source of carbon

Medium used of Lochhead \& Burton slightly modified. Dibasic potassium phosphate $(0.650 \mathrm{~g} . / 1$.$) and monobasic potassium phos-$ phate $(0 \cdot 350$ g./l.) were used; yeast extract, $0.01 \% ;$ pH 6.8
Morris (1960),

Clark (1955)

Morris (1960)

Morris (1960)

Lochhead \& Burton (1957)

Harvesting and preparation of organisms. The organisms were removed from the growth medium by centrifugation and immediately resuspended in a carbohydratefree medium, otherwise identical to the respective growth media. The final concentrations of organisms, as determined with a Klett-Summerson colorimeter, ranged from the equivalent of 0.5 to $1.5 \mathrm{mg}$. dry wt./ml. medium.

${ }^{14} \mathrm{C}$ Labelled compounds. $\left[1^{-14} \mathrm{C}\right]$ glucose, $\left[2-{ }^{14} \mathrm{C}\right]$ glucose, $\left[3^{-14} \mathrm{C}\right]$ glucose and $\left[6^{-14} \mathrm{C}\right]-$ glucose were obtained from the National Bureau of Standards through the kind co-operation of Dr H. S. Isbell. $\left[3,4-{ }^{14} \mathrm{C}\right]$ Glucose was prepared in this laboratory from liver glycogen of rats metabolizing ${ }^{14} \mathrm{CO}_{2}$ according to the method of Wood, Lifson \& Lorber (1945). [1-14C]Gluconate was purchased from the Nuclear Chicago Corporation. $\left[{ }^{2-14} \mathrm{C}\right]$ Gluconate, $\left[3^{-14} \mathrm{C}\right]$ gluconate, $\left[3,4-{ }^{14} \mathrm{C}\right]$ gluconate and $\left[6^{-14} \mathrm{C}\right]$ gluconate were prepared from the corresponding labelled glucose samples by the method of Moore \& Link (1940).

Radio-respirometry. The radio-respirometric experiments were carried out according to the procedures described by Wang et al. (1958) with $10 \mathrm{ml}$. of a given suspension of organisms for each of the experiments. Respiratory $\mathrm{CO}_{2}$ produced by the organisms was trapped with $10 \mathrm{ml}$. of $0.25 \mathrm{~N}$-ethanolic hyamine hydroxide (trade name for $p$-diisobutylcresoxyethoxyethyl, Rohm and Haas Co. Philadelphia, Pa., U.S.A.) which was replaced at hourly intervals. The radio-respirometric experiment was terminated when the assay of the radioactivity of ${ }^{14} \mathrm{CO}_{2}$ indicated that the labelled substrate had been exhausted from the medium. At that time, the suspension of organisms in the incubation flask was chilled with ice for about $15 \mathrm{~min}$. and the organisms separated from the incubation medium by centrifugation. The clear medium and the washed organisms were then processed for the measurement of radioactivity. 
Assay of radioactivity. The radioactivity in the respiratory $\mathrm{CO}_{2}$, in the form of ethanolic hyamine carbonate, was assayed by means of the liquid scintillation counting technique in the manner described by Wang \& Ikeda (1961). Countings were carried out over a sufficient period of time so that the counting data would carry a standard deviation no greater than $2 \%$. The radioactivity in organisms and incubation media was also counted by the use of the liquid scintillation counter. The counting samples in the nature of thioxotropic gel, were usually prepared with $1 \mathrm{ml}$. of either the aqueous suspension of organisms or the incubation medium with $14 \mathrm{ml}$. of the gel preparation made according to the procedures of White \& Helf (1956). The radioactivity of the labelled substrate was determined by procedures for sample preparation and counting identical with those used for ${ }^{14} \mathrm{CO}_{2}$ samples or organism and medium samples, respectively. The counting efficiencies of the liquid scintillation counting with respect to the various forms of counting samples were determined by the use of internal ${ }^{14} \mathrm{C}$ standards. The details of the liquid scintillation counting procedures are published elsewhere (Wang, 1962).

\section{RESULTS}

The complete substrate inventory of the radio-respirometric experiments on the utilization of glucose or gluconate for the five Arthrobacter species are given in Table 2. The data presented are those observed at the end of each experiment. The time-course plots of radio-respirometric data are given in Figs. 1-4 as typical examples. An examination of the data leads one to conclude that the five Arthrobacter strains examined in the present work can be divided into two major groups. In the first group, which consists of Arthrobacter globiformis (Figs. 1, 2) and A. ureafaciens, one finds that the radio-respirometric patterns for the utilization of glucose are basically different from the patterns for the assimilation of gluconate, whereas in the second group, which consists of $A$. simplex, A. pascens and A. atrocyaneus, there exists a remarkable resemblance when the radio-respirometric patterns for

Table 2. Substrate inventory of the radio-respirometric experiments on the utilization of glucose or gluconate by 5 Arthrobacter species.

\begin{tabular}{|c|c|c|c|c|c|c|c|}
\hline \multirow[b]{2}{*}{ Species } & \multirow{2}{*}{$\begin{array}{c}\text { Conc. of } \\
\text { organism } \\
\text { mg. dry wt./ } \\
10 \text { ml.) }\end{array}$} & \multicolumn{2}{|l|}{ Substrate } & \multicolumn{4}{|c|}{ Substrate inventory,* $(\%)$} \\
\hline & & Labelling & $\begin{array}{c}\mathrm{mg} . / \\
10 \mathrm{ml} .\end{array}$ & $\begin{array}{c}\text { Resp. } \\
\mathrm{CO}_{2}\end{array}$ & $\begin{array}{l}\text { Organ- } \\
\text { isms }\end{array}$ & Medium & Total \\
\hline \multirow{12}{*}{$\begin{array}{c}\text { Arthrobacter } \\
\text { ureafaciens }\end{array}$} & \multirow[t]{12}{*}{8} & {$\left[1-^{14} \mathrm{C}\right]$ Glucose } & $\mathbf{5}$ & 34 & 57 & 4 & 95 \\
\hline & & [2-14 C]Glucose & 5 & 28 & 57 & 8 & 93 \\
\hline & & [3-14C]Glucose & 5 & 49 & 38 & 9 & 96 \\
\hline & & {$\left[3,4 \sim^{14} \mathrm{C}\right]$ Glucose } & 5 & 57 & 34 & 5 & 96 \\
\hline & & {$\left[4-{ }^{-14} \mathrm{C}\right]$ Glucose $\dagger$} & - & 65 & $\ldots$ & - & - \\
\hline & & {$\left[6-{ }^{14} \mathrm{C}\right]$ Glucose } & 5 & 29 & 60 & $\mathbf{5}$ & 94 \\
\hline & & {$\left[1-{ }^{14} \mathrm{C}\right]$ Gluconate } & $2 \cdot 5$ & 79 & 2 & 20 & 101 \\
\hline & & {$\left[2-{ }^{14} \mathrm{C}\right]$ Gluconate } & $2 \cdot 5$ & 25 & 65 & 8 & 98 \\
\hline & & [3-14 C]Gluconate & $2 \cdot 5$ & 28 & 55 & 2 & 85 \\
\hline & & {$[3,4-14 \mathrm{C}]$ Gluconate } & $2 \cdot 5$ & 44 & 47 & $\overline{3}$ & 94 \\
\hline & & {$\left[4-^{-14} \mathrm{C}\right]$ Gluconate $\dagger$} & - & 59 & - & - & - \\
\hline & & [6-14C]Gluconate & $2 \cdot 5$ & 23 & 68 & 6 & 97 \\
\hline
\end{tabular}


Organism

\begin{tabular}{|c|c|c|c|c|c|c|c|}
\hline \multirow[b]{2}{*}{ Species } & \multirow{2}{*}{$\begin{array}{c}\text { Conc. of } \\
\text { organism } \\
\text { mg. dry wt./ } \\
10 \mathrm{ml} \text {.) }\end{array}$} & \multicolumn{2}{|l|}{ Substrate } & \multicolumn{4}{|c|}{ Substrate inventory,* $(\%)$} \\
\hline & & Labelling & $\begin{array}{l}\mathrm{mg} \cdot / \\
10 \mathrm{ml} .\end{array}$ & $\begin{array}{c}\text { Resp. } \\
\mathrm{CO}_{2}\end{array}$ & $\begin{array}{c}\text { Organ- } \\
\text { isms }\end{array}$ & Medium & Total \\
\hline \multirow[t]{12}{*}{ A. globiformis } & \multirow[t]{12}{*}{8} & {$[1-14 \mathrm{C}]$ Glucose } & 8 & 48 & 45 & 3 & 96 \\
\hline & & [2-14 C]Glucose & 8 & 28 & 69 & 2 & 99 \\
\hline & & {$\left[3^{-14} \mathrm{C}\right]$ Glucose } & 8 & 32 & 65 & 5 & 102 \\
\hline & & {$\left[3,4-^{-14} \mathrm{C}\right]$ Glucose } & 8 & 43 & 47 & 4 & 94 \\
\hline & & {$[4-14 \mathrm{C}]$ Glucose $\dagger$} & 一 & 54 & - & - & - \\
\hline & & {$\left[6-{ }^{14} \mathrm{C}\right] \mathrm{Glucose}$} & 8 & 21 & 69 & 4 & 94 \\
\hline & & {$\left[1-{ }^{14} \mathrm{C}\right]$ Gluconate } & 10 & 82 & 4 & 13 & 99 \\
\hline & & {$\left[2-{ }^{14} \mathrm{C}\right]$ Gluconate } & 10 & 37 & 51 & $\mathbf{5}$ & 93 \\
\hline & & {$\left[3-{ }^{14} \mathrm{C}\right]$ Gluconate } & 10 & 25 & 64 & 9 & 98 \\
\hline & & {$\left[3,4^{-14} \mathrm{C}\right]$ Gluconate } & 10 & 39 & 56 & 4 & 99 \\
\hline & & {$\left[4-{ }^{14} \mathrm{C}\right]$ Gluconate $\dagger$} & - & 54 & - & - & - \\
\hline & & {$\left[6^{-14} \mathrm{C}\right]$ Gluconate } & 10 & 18 & 69 & 6 & 93 \\
\hline \multirow[t]{12}{*}{ A. simplex } & \multirow[t]{12}{*}{15} & {$\left[1{ }^{14} \mathrm{C}\right]$ Glucose } & $\mathbf{2 \cdot 5}$ & 77 & 22 & $\mathbf{3}$ & 102 \\
\hline & & {$[2-14 \mathrm{C}]$ Glucose } & $2 \cdot 5$ & 35 & 59 & $\mathbf{3}$ & 97 \\
\hline & & [3-14C]Glucose & $2 \cdot 5$ & 24 & 70 & 3 & 97 \\
\hline & & {$\left[3,4,{ }^{14} \mathrm{C}\right]$ Glucose } & $2 \cdot 5$ & 32 & 58 & $\mathbf{5}$ & 95 \\
\hline & & {$[4-14 \mathrm{C}]$ Glucose } & - & 40 & - & - & - \\
\hline & & {$\left[6^{-14} \mathrm{C}\right]$ Glucose } & $2 \cdot 5$ & 28 & 65 & $\mathbf{3}$ & 96 \\
\hline & & {$\left[1 .{ }^{14} \mathrm{C}\right]$ Gluconate } & $2 \cdot 5$ & 74 & 12 & 16 & 102 \\
\hline & & {$\left[2-{ }^{14} \mathrm{C}\right]$ Gluconate } & $2 \cdot 5$ & 39 & 54 & $\mathbf{3}$ & 95 \\
\hline & & {$\left[3^{-14} \mathrm{C}\right]$ Gluconate } & $\mathbf{2 \cdot 5}$ & 24 & 72 & 4 & 100 \\
\hline & & {$\left[3,4^{-14} \mathrm{C}\right]$ Gluconate } & $\mathbf{2 \cdot 5}$ & 33 & 57 & $\mathbf{5}$ & 95 \\
\hline & & {$[4-14 \mathrm{C}]$ Gluconate $\dagger$} & - & 43 & - & - & - \\
\hline & & {$\left[6-{ }^{14} \mathrm{C}\right]$ Gluconate } & $2 \cdot 5$ & 22 & 72 & $\mathbf{3}$ & 97 \\
\hline \multirow[t]{12}{*}{ A. pascens } & \multirow[t]{12}{*}{12} & [1-14C]Glucose & 10 & 80 & 17 & 7 & 104 \\
\hline & & {$\left[2-{ }^{14} \mathrm{C}\right]$ Glucose } & 10 & 51 & 35 & 9 & 95 \\
\hline & & [3-14C]Glucose & 10 & 53 & 35 & 9 & 97 \\
\hline & & {$[3,4-14 \mathrm{C}]$ Glucose } & 10 & 65 & 21 & 12 & 98 \\
\hline & & {$\left[4-{ }^{14} \mathrm{C}\right]$ Glucose $\dagger$} & 一 & 77 & - & 一 & - \\
\hline & & [6-14C]Glucose & 10 & 32 & 52 & 8 & 92 \\
\hline & & {$[1-14 \mathrm{C}]$ Gluconate } & $\mathbf{5}$ & 82 & $\mathbf{5}$ & 6 & 93 \\
\hline & & [2-14C]Gluconate & 5 & 50 & 37 & 10 & 97 \\
\hline & & {$\left[3-{ }^{14} \mathrm{C}\right]$ Gluconate } & 5 & 43 & 47 & 8 & 98 \\
\hline & & {$\left[3,4^{-14} \mathrm{C}\right]$ Gluconate } & $\mathbf{5}$ & $\mathbf{5 5}$ & 30 & 10 & 95 \\
\hline & & {$[4-14 \mathrm{C}]$ Gluconate $\dagger$} & - & 66 & - & - & - \\
\hline & & {$\left[6-{ }^{14} \mathrm{C}\right]$ Gluconate } & $\mathbf{5}$ & 31 & 50 & 8 & 89 \\
\hline \multirow[t]{12}{*}{ A. atrocyaneus } & \multirow[t]{12}{*}{12} & {$[1-14 \mathrm{C}]$ Glucose } & 5 & 88 & 12 & 4 & 104 \\
\hline & & {$\left[2-{ }^{14} \mathrm{C}\right]$ Glucose } & 5 & 57 & 33 & 5 & 95 \\
\hline & & {$[3-14 \mathrm{C}]$ Glucose } & 5 & 51 & 42 & 5 & 98 \\
\hline & & {$\left[3,4^{-14} \mathrm{C}\right]$ Glucose } & 5 & 58 & 36 & 3 & 97 \\
\hline & & {$[4-14 \mathrm{C}]$ Glucose $\dagger$} & 一 & 65 & - & - & 一 \\
\hline & & {$\left[6^{-14} \mathrm{C}\right]$ Glucose } & $\mathbf{5}$ & 22 & 64 & 8 & 94 \\
\hline & & {$\left[1-{ }^{14} \mathrm{C}\right]$ Gluconate } & $\mathbf{5}$ & 80 & $\mathbf{3}$ & 10 & 93 \\
\hline & & [2-14 C]Gluconate & $\mathbf{5}$ & 63 & 28 & 4 & 95 \\
\hline & & {$\left[3^{-14} \mathrm{C}\right]$ Gluconate } & $\mathbf{5}$ & 50 & 43 & 5 & 98 \\
\hline & & {$\left[3,4^{-14} \mathrm{C}\right]$ Gluconate } & $\mathbf{5}$ & 53 & 34 & 8 & 95 \\
\hline & & {$\left[4^{-14} \mathrm{C}\right]$ Gluconate $\uparrow$} & - & 56 & - & - & - \\
\hline & & {$\left[6^{-14} \mathrm{C}\right]$ Gluconate } & $\mathbf{5}$ & 27 & 62 & 8 & 97 \\
\hline
\end{tabular}

Table 2 (cont.)

* Substrate inventory data are those collected at the end of each radio-respirometric experiment. $\uparrow$ Data were calculated from experimental findings from the $3^{-14} \mathrm{C}$ glucose and the $3,4^{14} \mathrm{C}$ glucose experiments. 
glucose utilization (Fig. 3, Table 2) and those for the utilization of gluconate (Fig. 4, Table 2) are compared.

It appears that in the Arthrobacters of the first group, glucose is not catabolized by way of gluconate or phosphorylated gluconate, whereas, in the second group, gluconate is the predominant, if not exclusive, intermediate for glucose catabolism. In as much as there exists a drastic difference in the catabolic behaviours of these two groups of Arthrobacter, detailed analysis of the radio-respirometric patterns, with respect to the identification of catabolic pathways functioning in these organisms, will be presented separately under the two stated different groups. To facilitate the analysis of the radio-respirometric data collected in the present work previous findings about the extent of $\mathrm{CO}_{2}$ formation from each of the carbon atoms

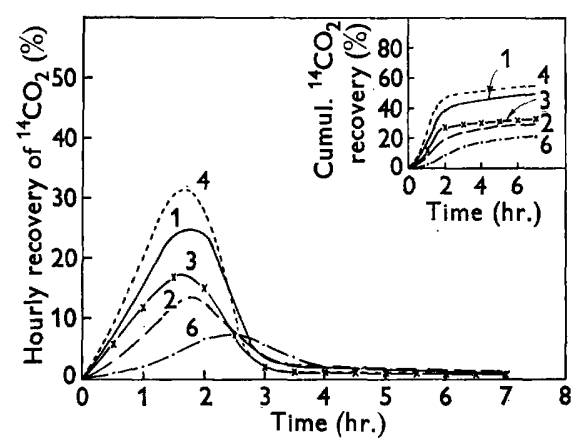

Fig. 1

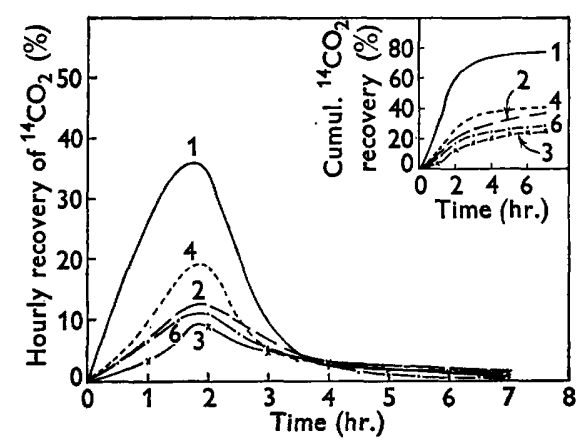

Fig. 3

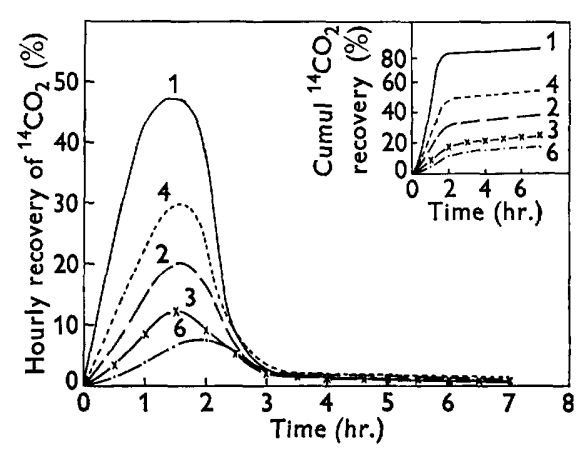

Fig. 2

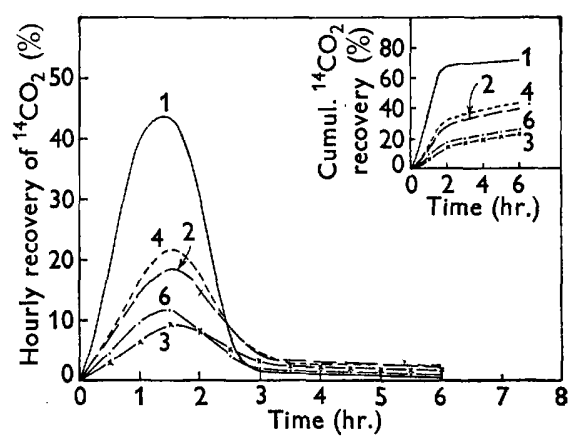

Fig. 4

Fig. 1. Radio-respirometric pattern for the utilization of glucose by Arthrobacter globiformis. [1-14 C]Glucose, $\longrightarrow ;\left[2-{ }^{14} \mathrm{C}\right]$ Glucose, $\cdots \cdots ;[3-14 \mathrm{C}]$ Glucose, $-x-x-x-;\left[4-^{14} \mathrm{C}\right]$ Glucose, -..--.-- $\left[6^{-14} \mathrm{C}\right] \mathrm{Glucose},-\cdot . . .-\cdot$.

Fig. 2. Radio-respirometric pattern for the utilization of gluconate by Arthrobacter globiformis. [1-14 C]Gluconate, $-;\left[2^{-14} \mathrm{C}\right]$ Gluconate, $\ldots--;\left[3^{-14} \mathrm{C}\right] \mathrm{Gluconate}$, $-x-x-x-;\left[4{ }^{14} \mathrm{C}\right]$ Gluconate, -...-.-.-; [6-14 C]Gluconate, -.........

Fig. 3. Radio-respirometric pattern for the utilization of glucose by Arthrobacter simplex. $\left[1^{-14} \mathrm{C}\right]$ Glucose, $\longrightarrow ;\left[2-{ }^{14} \mathrm{C}\right]$ Glucose, $-\cdots--;\left[3^{-14} \mathrm{C}\right]$ Glucose, $-x-x-x-;\left[4-{ }^{14} \mathrm{C}\right] \mathrm{Glucose}$, ......-; [6-14C]Glucose, ..........

Fig. 4. Radio-respirometric pattern for the utilization of gluconate by Arthrobacter simplex. $\left[1^{14} \mathrm{C}\right]$ Gluconate, $--;\left[2-{ }^{14} \mathrm{C}\right]$ Gluconate, $-\cdots ;\left[3-{ }^{14} \mathrm{C}\right]$ Gluconate, $-x-x-x-$; [4-14 C]Gluconate, -......-; [6-14 C]Gluconate, -......... 
of glucose by various pathways operative in micro-organisms are summarized in Fig. 5, which serves as a reference for recognizing the major glucose pathways in Arthrobacter.

\section{Arthrobacter species of group 1}

Arthrobacter ureafaciens. With glucose as substrate, the extensive recovery of C-4 and C-3 of glucose in $\mathrm{CO}_{2}$ (Fig. 1, Table 2) points to the operation of the EMP pathway in conjunction with the oxidative decarboxylation of pyruvate as the principal route for glucose assimilation. The product of this sequence, acetate, is presumably catabolized by the TCA cycle. Preliminary work with $A$. ureafaciens indicated that acetate was readily utilized, although it is not a carbon source which supports proliferation. The fact that $\mathrm{C}-1$ of glucose is converted to $\mathrm{CO}_{2}$ to an extent

\begin{tabular}{|c|c|c|}
\hline Pathways & & $\mathrm{CO}_{2}$ yields $(\%)$ \\
\hline & & $\begin{array}{ll}0 & 50\end{array}$ \\
\hline $\begin{array}{l}\text { Major: EMP-TCA } \\
\text { Minor: HMP }\end{array}$ & $\left|\begin{array}{l}1 \\
3 \\
3 \\
5 \\
6\end{array}\right|$ & בת \\
\hline $\begin{array}{l}\text { Major: EMP-TCA } \\
\text { Minor: HMP }\end{array}$ & $\left|\begin{array}{ll}1 & 2 \\
3 & 2 \\
5 & 4 \\
6\end{array}\right|$ & $=9$ \\
\hline $\begin{array}{l}\text { Major: EMP-TCA } \\
\text { Major: HMP }\end{array}$ & $\left|\begin{array}{ll}1 & 2 \\
3 & 4 \\
5 & 6\end{array}\right|$ & ב-1 \\
\hline Major: ED & 32 & 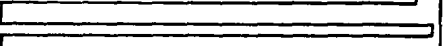 \\
\hline Major: ED-TCA & $\left|\begin{array}{l}2 \\
3 \\
5\end{array}\right|$ & $=1$ \\
\hline $\begin{array}{l}\text { Major: ED-TCA } \\
\text { Minor: HMP }\end{array}$ & $\left|\begin{array}{lll}1 & 2 \\
3 & 4 \\
5 & 6\end{array}\right|$ & 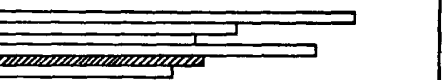 \\
\hline Major: PC-TCA & $\begin{array}{l}3 \\
3 \\
5\end{array}$ & 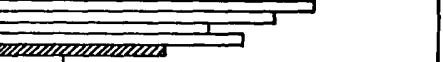 \\
\hline Major: PC & $\begin{array}{l}2 \\
3+4\end{array}$ & 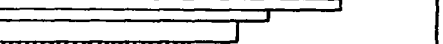 \\
\hline
\end{tabular}

Fig. 5. The relative yield of $\mathrm{CO}_{2}$ from glucose catabolized by different pathways in micro-organisms. Data taken from references given as follows in the order of the pathway combinations shown in the figure.

Major: EMP-TCA; Minor: HMP (Wang \& Krackov, 1962).

Major: EMP-TCA; Minor: HMP (Isono \& Wang; unpublished work on baker's yeast.) Major: EMP-TCA; Major: HMP (Wang \& Krackov, unpublished work on C. utilis.)

Major: ED (Stern, Wang \& Gilmore, 1960).

Major: ED-TCA (Stern, Wang \& Gilmore, 1960).

Major: ED-TCA; Minor: HMP (Stern, et al. 1960).

Major: PC-TCA (Wang \& Bjerre, 1961).

Major: PC (Kitos et al. 1958).

E Represents values estimated from theoretical considerations.

The numbers in the second column refer to the six carbon atoms of glucose. 
slightly greater than that of C-6 suggests that an alternative pathway is also operative in this organism. The nature of the alternative pathway is shown by examination of the radio-respirometric data for gluconate utilization by $A$. ureafaciens grown on gluconate (Table 2). The data can be interpreted on the basis of the concurrent operation of two catabolic sequences, namely the HMP pathway and the EntnerDoudoroff (ED) pathway, since in either case one would find that C-1 and C-4 of gluconate are preferentially converted to $\mathrm{CO}_{2}$ when compared with other carbon atoms. The exclusive operation of the ED pathway for gluconate assimilation is readily ruled out on the ground that the ${ }^{14} \mathrm{CO}_{2}$ yield from $\mathrm{C}-1$ is considerably greater than that from $\mathrm{C}-4$. The observed gluconate pattern, in fact, points to the operation of the HMP pathway which converts gluconate, upon phosphorylation, to fructose6-phosphate (F-6-P) which is in turn catabolized in a manner identical with that of substrate glucose, i.e. primarily by the EMP pathway. The conclusion is drawn from a comparison of the observed ${ }^{14} \mathrm{CO}_{2}$ yields from gluconate carbon atoms with that calculated on the basis of the following catabolic sequence:

$$
\begin{aligned}
& \text { gluconate } \rightarrow \text { 6-phosphogluconate } \rightarrow \text { pentose phosphate } \rightarrow \text { fructose-6-phosphate } \rightarrow \\
& \text { Predominantly } \\
& \rightarrow \quad \text { fructose-1,6-phosphate } \stackrel{\text { EMP }}{\longrightarrow} \text { triose phosphate } \rightarrow \text { acetyl CoA, etc. } \\
& \stackrel{\text { glucose-6-phosphate } \rightarrow 6 \text {-phosphogluconate } \rightarrow \text { pentose phosphate, etc. }}{\longrightarrow}
\end{aligned}
$$

Details of the method of calculation have been reported elsewhere in connexion with studies on the catabolism of glucose and gluconate in Bacillus subtilis (Wang \& Krackov, 1962).

As shown in Table 3, the calculated ${ }^{14} \mathrm{CO}_{2}$ yields from gluconate carbon atoms are in close agreement with the corresponding values observed experimentally. This fact thus supports the contention that in Arthrobacter ureafaciens, glucose is metabolized mainly by way of the EMP-TCA sequence and, to a limited extent, by way

Table 3. Conversion of gluconate carbon atoms to respiratory $\mathrm{CO}_{2}$ by Arthrobacter organisms

$\begin{array}{ccc}\begin{array}{c}\text { Gluconate carbon } \\ \text { atoms }\end{array} & \begin{array}{c}\text { Calculated yield } \\ \text { in respiratory } \mathrm{CO}_{2}{ }^{*} \\ \text { (\% of substrate) } \\ \text { Arthrobacter ureafaciens }\end{array} & \begin{array}{c}\text { Observed yield } \\ \text { in respiratory } \mathbf{C O}_{2} \\ \text { (\% of substrate) }\end{array} \\ 1 & - & 79 \\ 2 & 31 & 26 \\ 3 & 28 & 27 \\ 4 & 51 & 59 \\ 5 & - & 23 \\ 6 & 23 & \\ 1 & \text { Arthrobacter globiformis } & 82 \\ 2 & - & 37 \\ 3 & 35 & 25 \\ 4 & 24 & 54 \\ 5 & 44 & 18 \\ 6 & - & \end{array}$

* Calculated on the basis of the catabolic sequence depicted in Fig. 6. Procedures described by Wang \& Krackov (1962). 
of the HMP pathway depicted in Fig. 6. The participation of each of the two recognized catabolic sequences in the overall glucose catabolism has been estimated according to the method of Wang \& Krackov (1962). It appears that in $A$. ureafaciens, substrate glucose is catabolized $93 \%$ by the EMP pathway and $7 \%$ by the HMP pathway.

Arthrobacter globiformis. The radio-respirometric pattern for glucose utilization by this organism resembles to some extent that of $A$. ureafaciens except that in $A$. globiformis $\mathrm{C}-1$ of glucose is converted much more extensively to respiratory $\mathrm{CO}_{2}$.

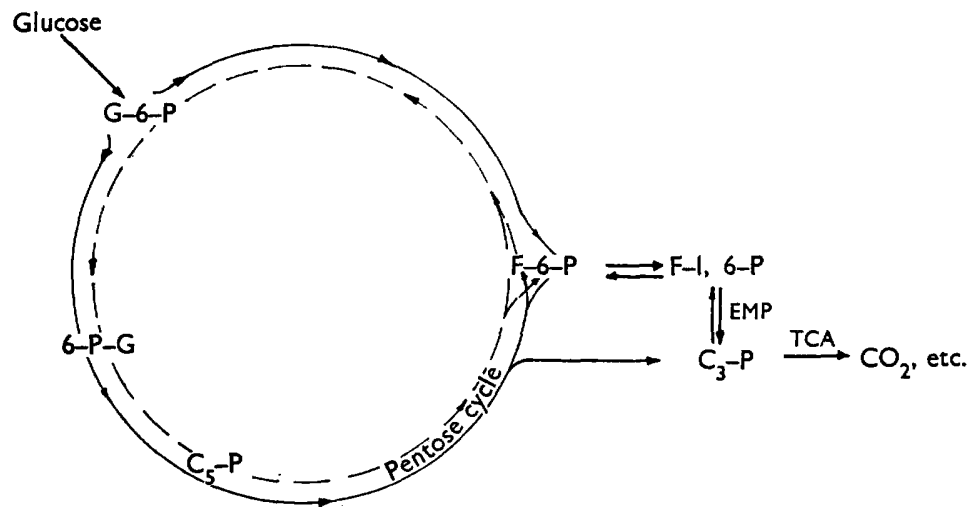

Fig. 6. The catabolic mechanism of glucose in Arthrobacter ureafaciens and A. globiformis. Primary pathway, __ secondary re-cycling pathway, . . . . . . . .

This can be accounted for on the basis that the HMP pathway plays a more important role in the assimilation of glucose in $\boldsymbol{A}$. globiformis. Data analysis was carried out in the manner similar to that described under $A$. ureafaciens to calculate the yields of $\mathrm{CO}_{2}$ from gluconate carbon atoms, on the basis that gluconate was catabolized by the HMP-EMP sequence (Fig. 6). Once again the operation of the HMP-EMP sequence is confirmed by the close agreement reached between the calculated and observed values (Table 3). The participation of each of the catabolic sequences for glucose assimilation was then estimated, according to Wang \& Krackov (unpublished), on the basis of the foregoing understanding. It appears that $68 \%$ of the substrate glucose was catabolized by the EMP pathway, whereas the HMP-EMP pathway was responsible for the catabolism of $32 \%$ of the substrate glucose. The findings are in good agreement with those reported by Morris (1960) where a different method for pathway estimation was used.

\section{Arthrobacter species of group 2}

Arthrobacter'simplex. The Arthrobacter species in group 2 appear to metabolize glucose by the intermediary formation of gluconate. The conclusion is drawn from the remarkable resemblance observed when the radio-respirometric pattern for (glucose utilization Fig. 3) is comdared with that of gluconate utilization (Fig. 4). In fact, these patterns remind one of the catabolic behaviour displayed by the pseudomonads (Stern, Wang \& Gilmour, 1960). A possible phylogenetic link between the genera Arthrobacter and Pseudomonas, through the motile plant-pathogenic corynebacteria, has already been suggested by Jensen (1952). 
With Arthrobacter simplex, the radio-respirometric patterns indicate that the EMP pathway is not operative, or else plays a rather minor role in this organism, since extensive conversion of C-3 or C-4 of glucose to $\mathrm{CO}_{2}$ was not observed. Instead, the patterns can be best interpreted as representing the occurrence of the EntnerDoudoroff (ED) pathway and the HMP pathway concurrently. This conclusion is drawn from the fact that the metabolic equivalence between C-1 and C-4 of either glucose or gluconate is not realized, thus ruling out the exclusive operation of the ED pathway. The exact nature of the HMP pathway which functions in $A$. simplex cannot be readily recognized by the findings of the present work. Estimation of pathway participation according to Wang et al. (1958) indicated that $76 \%$ and $24 \%$ of the substrate gluconate were catabolized by the ED pathway and the HMP pathway, respectively. With glucose as substrate, the ED pathway participated to the extent of $65 \%$ of the total glucose assimilated. The remaining $35 \%$ of the substrate glucose was presumably catabolized by HMP pathway.

Arthrobacter pascens. In close resemblance to the catabolic mechanisms operative in $A$. simplex, glucose was catabolized in $A$. pascens via gluconate by the concurrent operation of the Entner-Doudoroff (ED) and HMP pathways. However, in view of the fact that C-4 of glucose or gluconate was extensively converted to respiratory $\mathrm{CO}_{2}$ it is reasonable to assume that the ED pathway plays a more important role in the overall carbohydrate catabolism of this organism. An estimation made according to the method described for pseudomonads (Stern, et al. 1960) revealed that glucose. was catabolized $94 \%$ and $6 \%$, respectively, by the ED and HMP pathways, whereas gluconate was catabolized $82 \%$ and $18 \%$, respectively, by the ED and HMP pathways.

Arthrobacter atrocyaneus. Nothing is known about the catabolic mechanisms operative in this recently isolated organism. The radio-respirometric data for the utilization of glucose and gluconate by $A$. atrocyaneus (Table 2) revealed a rather interesting catabolic behaviour. The pattern for glucose utilization resembles basically those of $A$. pascens and $A$. simplex, which suggests that glucose may have been catabolized primarily by the Entner-Doudoroff pathway in conjunction with the HMP pathway in A. atrocyaneus. On the other hand, the conversion of C-6 of glucose to $\mathrm{CO}_{2}$ by $A$. atrocyaneus proceeded at a much slower rate, resulting in an overall recovery of $\left[6^{-14} \mathrm{C}\right]$ glucose in $\mathrm{CO}_{2}$ amounting to only $20 \%$ at the end of the experiment. Moreover, the conversion of $\mathrm{C}-3$ of glucose to $\mathrm{CO}_{2}$ was much more pronounced than that of $\mathrm{C}-6$, leading one to believe that the product of the HMP pathway may have participated more extensively in the pentose cycle pathway than the cases of the other two Arthrobacter species in this group.

With Arthrobacter atrocyaneus there were also several significant differences between the radio-respirometric pattern for glucose utilization and that for gluconate utilization (Table 2). With gluconate, the conversion of $\mathrm{C}-4$ of gluconate to $\mathrm{CO}_{2}$ was not too extensive and the order of $\mathrm{CO}_{2}$ production from other carbon atoms, i.e. $\mathrm{C}-1>\mathrm{C}-2>\mathrm{C}-3>\mathrm{C}-6$, is reminiscent of the radio-respirometric patterns observed with Acetobacter suboxydans (Kitos et al. 1958) and A. melanogenum (Wang \& Bjerre, 1961). It is known that in these two organisms, gluconate is catabolized primarily by the pentose cycle pathway. However, the exact nature of the catabolic mechanism functioning in $A$. atrocyaneus cannot be clearly defined in the present study. 


\section{DISCUSSION}

One modern trend in bacterial taxonomy endeavours to show natural phylogenetic relationships between groups of micro-organisms. This can perhaps be achieved by a proper evaluation of differential criteria, including morphological and physiological aspects. The relative usefulness of each of these aspects obviously differs from group to group. The emphasis on any given characteristics or set of characteristics in determining the taxonomic position of a particular organism remains largely a matter of personal choice. This accounts for the unsettled situation with regard to the taxonomic status of the genus Arthrobacter. The nine recognized species in the genus have been grouped together mainly on account of striking morphological similarities which, for some microbiologists, undoubtedly point to a close taxonomic relationship. Cummins (1959), on the basis of studies on the cell-wall composition of several Arthrobacters pointed out the apparent heterogeneity of the group. On the basis of previous work with other Gram-positive bacteria, Cummins concluded that the amino acid pattern of the cell wall is of significance at approximately the generic level, whereas, the type of sugars and amino sugars present in the cell wall define species within the genus. On these grounds, Arthrobacter globiformis, A. ureafaciens, A. citreus, A. aurescens and A. pascens, containing alanine, glutamic acid and lysine in the cell wall, would constitute a fairly homogeneous group. On the other hand, A. simplex and A. tumescens, in which alanine, glutamic acid, glycine and LL-diaminopimelic acid are found in cell walls, should be classified as a separate group. This analysis led Cummins to conclude that the bacteria now classified in the genus Arthrobacter are those from a 'mixed origin'. The lack of uniformity among Arthrobacters has repeatedly appeared in the literature, particularly with regard to the marked differences observed in nutritional requirements among these organisms. In our work we noticed such differences which confronted us with difficulties in devising suitable media for growing our organisms.

Recently studies on the biochemical behaviour of different micro-organisms have been more systematic and the information so obtained has been used in the taxonomy of microbial species. A notable example is the work of DeLey (1961) in which a classification of the genus Acetobacter has been put forward which takes into consideration the catabolic behaviour of the organisms as well as morphological and physiological characteristics. In the case of Arthrobacter, Jensen (1952) considered this group of micro-organisms as being primitive and versatile in biosynthetic capabilities and accompanied by a catabolic mechanism highly oxidative in nature. Thus, in Jensen's phylogenetic scheme, Arthrobacter, as typified by A. globiformis, occupies a position among the coryneform bacteria similar to that of the 'pool of ancestors' as defined by DeLey (1961). Jensen suggested that pseudomonads might have had their origin in the coryneform bacteria, and the Gram-negative characteristic of the pseudomonads was explained on the grounds that the ability to store ribonucleic acid had gradually been lost. This is understandable if it can be recalled that a weak Gram reaction is exhibited by young Arthrobacter cultures. It may be mentioned that one of the outstanding catabolic characteristics of pseudomonads is the fact that the Entner-Doudoroff pathway is known, at the present time, to be operative primarily in this group of organisms. 
The diversified aspects of carbohydrate catabolism observed in the single strains of five Arthrobacter species in the present work are in accordance with Jensen's contention (1952) about phylogenetic development. Thus, one finds that on the one hand the Arthrobacter species in group 1 rely on the concurrent operation of the EMP and HMP pathways for glucose assimilation, pointing to a relationship with Propionibacterim, Mycobacterium and animal diphtheroids. On the other hand the Arthrobacters in group 2 appear to be related to the pseudomonads and Acetobacters, as indicated by the fact that glucose and gluconate are catabolized by these organisms primarily by way of the Entner-Doudoroff and the pentose cycle pathways.

It is not suggested that the understanding of catabolic patterns in microorganisms constitutes by any means the exclusive criteria to be used in microbial taxonomy. However, as suggested by the work of DeLey (1961) and the findings in the present work, the biochemical behaviour of micro-organisms does furnish useful information which may help to devise a better system for the establishment of their phylogenetic relationships. There exists a need for simple procedures for the identification and estimation of catabolic sequences in microbial system; the use of radio-respirometry in this regard is a good example.

This research was supported in part by grants from National Institutes of Health, U.S. Public Health Service and Gulbenkian Foundation, Lisbon, Portugal.

One of us (A.C.Z) was on leave from Agricultural Research Service, Ministry of Agriculture, Lisbon, Portugal.

\section{REFERENCES}

Bergey's Manual of Determinative Bacteriology. (1957). 7th ed. Ed. by R. S. Breed, E. G. D. Murray \& N. R. Smith. London: Baillière, Tindall \& Cox.

Chaplin, C. E. (1957). Life cycles in Arthrobacter pascens and Arthrobacter terregens. Canad. J. Microbiol. 3, 103.

ClARK, F. E. (1955). Designation of Corynebacterium ureafaciens Krebs and Eggleston as Arthrobacter ureafaciens, comb.nov. (Symposium on Taxonomy); Bact. Rev. $19,273$.

ConN, H. J. (1928). A type of bacteria abundant in productive soils, but apparently lacking in certain soils of low productivity. Bull. N.Y. St. Agric. Exp. Sta., no. 138.

ConN, H. J. \& Diммicк, (1947). Soil bacteria similar in morphology in Mycobacterium and Corynebacterium. J. Bact. 54, 291.

Cummins, C. S. (1959). Taxonomic position of Arthrobacter. Nature, Lond. 184, 831.

DELEY, J. (1961). Comparative carbohydrate metabolism and a proposal for a phylogenetic relationship of the acetic acid bacteria. J. gen. Microbiol. 24, 31.

Fukin, G. M. \& Vandermark, P. J. (1952). Evidence for the TCA cycle in Corynebacterium creatinovorans. J. Bact. 64, 887.

Chiretti, F. \& Barron, E. S. G. (1954). Pathway of glucose oxidation in Corynebacterium creatinovorans. Biochim. biophys. Acta, 15, 445.

Jensen, H. L. (1952). The coryneform bacteria. Annu. Rev. Microbiol. 6, 77.

Kitos, P. A., Wang, C. H., Mohler, B. A., King, T. E. \& Cheldelin, V. H. (1958). Glucose and gluconate dissimilation in Acetobacter suboxydans. J. biol. Chem. 233, 1295.

Kunn, D. A. \& Starr, M. P. (1960). Arthrobacter atrocyaneus, n.sp., and its blue pigment. Arch. Mikrobiol. 36, 175.

LochHEAD, A. G. (1958). Two new species of Arthrobacter requiring respectively vitamin $B_{12}$ and the 'terregens' factor. Arch. Mikrobiol. 31, 163.

Lochiead, A. G. \& Burton, M. O. (1953). An essential bacterial growth factor produced by microbial synthesis. Canad. J. Bot. 31, 7 . 
LochHead, A. G. \& BURTon, M. O. (1957). Qualitative studies of soil micro-organisms. XIV. Specific vitamin requirements of the predominant bacterial flora. Canad. J. Microbiol. 3, 35.

Morris, J. G. (1960). Studies on the metabolism of Arthrobacter globiformis. J. gen. Microbiol. 22, 564.

Moone, S. \& Link, K. P. (1940). Carbohydrate characterization. J. biol. Chem. 133, 293.

SAcks, L. E. (1954). Observations on the morphogenesis of Arthrobacter citreus, spec. J. Bact. 67, 342.

Stern, I. J., WANG, C. H. \& Gilmour, C. M. (1960). Comparative catabolism of carbohydrates in Pseudomonas species. J. Bact. 79, 601.

Sundman, V. (1958). Morphological comparison of some Arthrobacter species. Canad. J. Microbiol. 4, 221.

TAYLOR, C. B. (1938). Further studies of Bacterium globiforme and the incidence of this type of organism in Canadian soils. Soil Sci. 46, 307.

WaNG, C. H. (1962). Metabolism studies by radio respirometry. Atomlight, 21, 1.

WANG, C. H. \& BJERre, S. (1961). Comparative carbohydrate catabolism in Acetobacter species. Fed. Proc. 19, 84a.

Wang, C. H. \& IKeda, G. J. (1961). Biosynthesis of $\mathrm{C}_{4}$ acids in Pseudomonas fluorescens KB 1. Biochem. J. 79, 614 .

WANG, C. H. \& Krackov, J. K. (1962). The catabolic fate of glucose in Bacillus subtilis. J. biol. Chem. (in the Press).

Wang, C. H., Stern, I. J., Gilmour, C. M., Klungsoyr, S., Reed, D. J., Bialy, J. J., Christensen, B. E. \& Cheldelin, V. H. (1958). Comparative study of glucose catabolism by the radio-respirometric method. J. Bact. 76, 207.

White, C. G. \& Helf, S. (1956). Suspension counting in scintillation gels. Nucleonics, $14,46$.

Wood, H. G., LIfson, N. \& LoRBer, V. (1945). The position of fixed carbon in glucose from rat liver glycogen. J. biol. Chem. 159, 475. 